\title{
UN DIÁLOGO A TRES BANDAS
}

\author{
Mariano Brasa Díez \\ Universidad Autónoma de Madrid
}

\section{RESUMEN}

En esta obra de Abelardo: Dialogus inter philosophum, iudaeum et christianum vamos a encontrarnos con tres personajes que proceden de caminos distintos y de religiones distintas. Quiero fijarme en este trabajo no tanto en el qué sino en el cómo y en el dónde y nos vamos a las artes del Trivium. Esta obra escrita en su retiro de Cluny parece como si le volviera a sus años mozos, a sus luchas y a sus discusiones... Los personajes de esta altercatio van a ser un dialéctico (filósofo), un retor (cristiano) y un gramático (judío). El dialéctico que arguye contra el judío y el cristiano quiere llevarles hasta su campo, las artes del lenguaje, que Abelardo manejaba como nadie... Pero, además de esto, en el Dialogus Pedro Abelardo inaugura una tradición que favorecerá el uso de la razón para defender la fe

Palabras clave: Pedro Abelardo; artes del Trivium = gramática, retórica y dialéctica; filósofo, cristiano y judío.

\begin{abstract}
In this Abelarde's work called Dialogus inter philosophum, iudaeum et christianum we will find three personages that come from different ways and different religions. I want to play special attention not only to why but how and where living away the arts of the Trivium. This work written while Abelarde was living in retirement in Cluny, is like he went back to his young years, to his fightings, to his discusions... The personages of this altercatio will be a dialectician (Philosopher), a rethoric (Christian) and a grammarian (Jewish). The dialectic that argues against the Jewish and the Christian wants to guide then through the arts of languaje which manage as nobody do... Beside this, in the Dialogus... Abelarde open a new tradition which will help the use of the reason to protect the faith.
\end{abstract}

Key words: Peter Abelarde, arts of the Trivium = grammar, rhetoric and dialectic; dialectician, rhetorician and grammarian.

\section{LOS INTERLOCUTORES DE UN DIÁLOGO MEDIEVAL}

El Dialogus de Abelardo es algo que siempre me ha llamado la atención. Sus personajes proceden de caminos distintos y de religiones diferentes. Los tres adoran a un Dios único, pero no tienen ni la misma fe, ni el mismo modo de servir a Dios: el filósofo lee en la Ley Natural; el judío y el cristiano en el Talmud y en la Biblia, respectivamente. En esta obra Abelardo se plantea un problema que no inquietó a San Bernardo con el que ya estaba reconciliado, pero que apasionaría a la opinión cristiana. Al escribir esta obra en su retiro de Cluny, Abelardo inaugura una tradición importante y que va a favorecer el uso de la razón para la defensa de la fe, como lo harán un siglo después Alberto Magno y Tomás de Aquino al refutar a Averroes; Ramón Lull cuando entabla conversaciones con los sabios del islam y del judaísmo y, posteriormente, Nicolás de Cusa en su De pace fidei y R. Portel en su De orbis concordia. 
Pero, a pesar de todo esto, lo que me ha animado a hacer este trabajo no es lo que en el Diálogo se dice sino el marco general y el modelo conforme al cual las cosas se dicen. El contenido del Diálogo es bien conocido ${ }^{1}$. Por el contrario, el entramado central donde se encuentran los principales datos, creo que no ha sido lo suficientemente estudiado. Es verdad que el Diálogo contiene las ideas y los temas generales conocidos de la apologética del tiempo ${ }^{2}$; pero falta lo referencial. A partir de lo cual, el escenario se organiza y, esto referencial, lo que hace que el Diálogo sea diferente, es precisamente el Trivium; la dialéctica, la retórica y la gramática. La idea de que las artes del Trivium sirven de propedéutica a la moral, no está subrayada solamente en una mera alusión, ni, menos todavía, traída como un elemento más ${ }^{3}$, sino que constituye la gozne fundamental sobre el que va a girar la altercatio ${ }^{4}$.

Desde esta perspectiva podemos afirmar que Abelardo articula el Diálogo como si estuviera pensando en una discusión entre un dialéctico, un retor y un gramático. Es como un volver la mirada hacia atrás. A sus años jóvenes, a sus luchas, a sus discusiones dialécticas... No pretendo que en esta ficción que resultaría del soñar despierto, los tres personaje sirvieran de alegoría a las artes del Trivium, simplemente creo que los argumentos invocados contra el judío y el cristiano manifiestan la intención de Abelardo de mantenerse decididamente en el lugar que no ha dejado nunca de ser el suyo y del que las «calamidades» no han podido desplazarle. Las artes del lenguaje eran su campo y sabía manejarlas como nadie. Creo que es a través de este entramado escolar y epistemológico dónde y cómo se dan perspectivas y percepciones sobre el otro. Primero sobre el judio, cuidadoso hasta la meticulosidad de la letra, del signo, de la literalidad como un gramático aferrado a las solas uniones constructivas de las palabras; del cristiano después, ingenuamente demasiado seguro, como el retor, de las autoridades exteriores sobre las que basa su predicación sin cuestionar la coherencia interna de su Verdad; finalmente del filósofo, campeón de la dialéctica en la que Abelardo insistió tanto que, para guardarla intacta contra el Occidente cristiano rebelde e intolerante, el deseo le llevó a fingir una adhesión a la fe musulmana.

Voy a tratar de leer el Dialogus a la luz de la Historia Calamitatum y esto va a permitirme poder dar vida, entorno y nombres a los personajes de esa ficticia altercatio.

\section{EL FILÓSOFO}

El origen del debate no es la religión sino la profesión del filósofo: «Mea, inquit, opera hoc est inceptum..». 5 . Todos están de acuerdo en que es necesario alcanzar la Verdad para asegurar la salvación del alma. El judío y el cristiano se remiten a la ley, mientras que el filósofo llega a la bienaventuranza a través de caminos diferentes: uno objetivo, la virtud; otro subjetivo, la dialéctica ${ }^{6}$. El filósofo dice más todavía cuando afirma que la salvación del alma pasa por la dialéctica y no por las obras ni los ritos ${ }^{7}$ y si el filósofo se coloca de parte de la religión

1 Cfr. R. THOMAS, Derphilosophisch-theologische Eskenntnismeg Peter Abaelards in Dialogus inter Philosophum, Judaeum et Christianum, Bonn, 1966; también su introducción a la edición crítica del Dialogus, Stuttgart, 1970; J. JOLIVET, Abélard, París, 1969; M. De GANDILLAC, la introducción a Oeuvres choisies d'Abélard, París, Aubier, 1945; R. ROQUES, Structures théologiques, París, 1962, págs. 260.264.

2 Cfr. R. ROQUES, op. cit.,

3 Cfr. J. JOLIVET, op. cit., págs. 91 y 93

4 Cfr. J. JOLIVET, Arts du langage te théologie chez Abélard, París, J, Vrin, 1969, pág. 334.

5 P. ABAELARDUS, Dialogus inter Philosophum, Judaeum et Christianum, ed. de Rudolf Thomas, Stuttgart, 1970, línea 15 (en el texto siempre utilizo esta edición de R, Thomas porque es la edición crítica).

6 Cfr. PH. DELHAYE, «Grammatica et Ethica au XIIe siècle», en Recherches de Théologie Ancienne et Médiévale, 25 (1958) 91.

7 Dialogus, ed. R. Thomas, línea 160-165. 
natural, es porque está fundada en la razón y esto quiere decir que es permanente, universal y se reduce a la esencial ${ }^{8}$. Nos encontramos ante una religión abierta a la dialéctica, ajustada a la ética de Séneca, de Cicerón y de Epicuro y en la que las categorías bien-mal funcionan como universales?.

Para el filósofo la religión natural es primera, universal e interior. Su superioridad le viene dada por el hecho de que la razón es anterior a la autoridad y a la historia; las obras, las prescripciones judías y cristianas son signos posteriores a la ley inscrita en el corazón de todo hombre $^{10}$. Esta ciencia primera, que se llama ética, se basa en documentis y no en scriptis $^{11}$, porque la razón, según las palabras de San Antonio, no tiene necesidad de escritos: «Puesto que el discernimiento de la razón es la fuente de los escritos, el que posea este discernimiento, no tiene necesidad de escritos» ${ }^{12}$. Prioridad, por tanto, de la razón no sólo temporal sino de naturaleza, como lo simple es anterior a lo compuesto ${ }^{13}$. Caracterizada así, esta religión se convierte en universal. Las religiones sometidas a la autoridad y a la historia están sujetas a lo contingente y al singularismo sociológico ${ }^{14}$. El lógico, por el contrario, prefiere lo universal y lo necesario y se comprende fácilmente que su elección vaya dirigida al ideal de los Patriarcas, anterior a toda ley positiva ${ }^{15}$. Las acomodaciones y las adaptaciones de las religiones positivas a las costumbres de los pueblos, a los decretos romanos y sinodales, llevan consigo demasiado de aleatorio y de externo para llegar al asentimiento de la fe por argumentos racionales ${ }^{16}$. La religión natural, por el contrario, es anterior y reside no tanto en el patrimonio de las autoridades, de las opiniones o de los signos, cuanto en una vía racional y dialéctica hacia la Verdad. Gracias a la dialéctica, la razón escoge sus propias autoridades ${ }^{17}$ y realiza, a su vez, la tentativa crítica ${ }^{18}$. Al llegar a este punto es cuando el filósofo inaugura y conduce el debate.

El personaje posee además rasgos islámicos. ¿Por qué? Las investigaciones hechas sobre esta cuestión tienden a resolver la dificultad por el sesgo de encuestas históricas y con la ayuda de modelos objetivos. Los datos objetivos y sociológicos, el juego de las influencias textuales e ideológicas nos proporcionan aquí una ayuda muy débil. No hay nada en el Dialogus que pueda darnos más que probabilidades. En este punto estamos condenados a la conjetura, a la representación muy vaga que Abelardo da del musulmán y a la presunción de tolerancia y de racionalismo que el propio Abelardo imagina estar de moda en el Islam ${ }^{19}$. Por mi parte prefiero no salirme del texto del Dialogus salvo para leer dentro del mismo texto el de la Historia Calamitatum. Doy por sentado que el escenario del Dialogus, fruto de la imaginación creadora de Abelardo, envía tanto al deseo y a la subjetividad del escritor como a los modelos exteriores o a las influencias objetivas que a duras penas ha probado ${ }^{20}$. El filósofo del Dialogus es el mismo que en la Historia Calamitatum había deseado practicar con el Islam al precio de cualquier tributo para ganar, a cambio, el derecho, desconocido en el Occidente cristiano, de ejercer en paz du oficio de dialéctico: «Dios lo sabe...deseé irme con los gentiles y permanecer allí,

8 Ibidem, 2220 y sigs.

9 Ibidem, 2335, 2349, 3169.

10 Ibidem, 243-245, 475, 525, 572.

11 Ibidem, 85, 86, 145, 1275.

12 Ibidem, 1410-1412.

13 Ibidem, 83-84

14 Ibidem, 575-588, 2225-2233, 2234-2245.

15 Ibidem, 332-340, 362-365.

16 Ibidem, 2238-2246.

17 Ibidem, 1402-1403.

18 Ibidem, 1404-1405.

19 Cfr. M. de GANDILLAC, «Sur quelques interprétations récentes d'Abelard», en Cahiers de civilisation médiévale, 4 (1961) 300, nota 30.

20 Cfr. J. JOLIVET, «Abélard et la Philosophie», en Revue de l'Histoire des Religions, 164 (1963) 189 
en cualquier parte $y$, entre los enemigos de Cristo, vivir criștianamente» ${ }^{21}$. Teniendo en cuenta este «christiane vivere» parece que el modelo de filósofo que nos presenta Abelardo en el Dialogus sea de tipo religioso, incluso teológico, conforme al lema del «inteligo ut credam». ¿Tenemos que acudir a Ibn Badja y a su reputación de filósofo desligado de toda fe religiosa...? ¿Es cierto que Abelardo quería introducir en su obra un filósofo químicamente puro? Yo me inclino a pensar que no es válida ninguna de las dos hipótesis. El Abelardo de la Historia Calamitatum es el errante, el fugitivo, el herético, el impuro: «Atónito y como llega de modo inesperado el resplandor del rayo, esperaba yo ser llevado ante concilios y sinagogas como hereje o profano»22, en cambio, el del Dialogus, es el filósofo comparado a los infieles: «... sed magis tue infidelitatis obstinatio dampnat» ${ }^{23}$, porque aquí el filósofo (Abelardo) se pone la máscara del Islam y de esta manera cumple su pacto con el mundo de la ficción. Pero este hijo simulado de Ismael conoce mejor la religión cristiana: «... non te ignorantia fidei nostre..». ${ }^{24}$, que la musulmana de la que finge ser adepto para tener la paz y poder filosofar; para ser dialéctico en paz. De hecho obtiene ventajas. Según el texto del Dialogus, que es ahora el escenario, se le reconoce en tierra musulmana lo que el Occidente latino le negó: la grandeza del genio. Y así es porque, desde el comienzo de la altercatio, es el filósofo el que, después de haber aplicado a Abelardo el bálsamo de la lisonja, alaba la profundidad de su espíritu, su erudición universal, su famosa reputación, su extraordinaria memoria, su superioridad sobre todos los contemporáneos, sus admirables escritos teológicos que la envidia no pudo soportar. Finalmente la gloria extraordinaria que alcanzó su nombre gracias a las persecuciones de las que fue objeto. Abelardo toma aquí, y de esta manera, revancha y el proscrito se concede un respiro que le consuela.

El contexto de la Historia Calamitatum y el del Dialogus ha cambiado y la situación es totalmente inversa: el deseo se ha desplazado y asistimos a la vuelta del reflujo. La Dialéctica estaba maltratada en Occidente y aquí y ahora afirma sus derechos caracterizados en los rasgos de un personaje musulmán reducido a su más simple expresión. La creación literaria permite realizar a veces esta clase de cambios y puede explicar, a su manera, lo que muchas veces las pruebas históricas y objetivas no realizan. La filosofía del Dialogus es la transcripción ficticia de un dialéctico cristiano que ha practicado con el Islam, lo que no implica, de hecho, que Abelardo se haya sometido. Los ejemplos de piedad dan prueba de esto que decimos. Lo que sucede es que el orden de los deseos no es el mismo que el orden de la realidad.

\section{EL CRISTIANO}

No es nada extraño que el terreno polémico sobre el que el filósofo encuentra al cristiano sea el de la dialéctica. El que en otro tiempo había querido que la dialéctica triunfara en la inteligencia de la fe, no podía olvidar que en su empeño sólo había encontrado virtuosismo verbal y resonante retórica. Abelardo no podía borrar la huella de los malos recuerdos: su estancia en la escuela de retórica del maestro Guillermo ${ }^{25}$, seguida de la enseñanza del maestro Anselmo, viejo de fácil palabra, pero carente de ideas y de razón ${ }^{26}$. Después, los ataques conciliares dirigidos por Alberico y Lotulfo que se preciaban no de tener en cuenta la fuerza de

21 P. ABAELARDUS, Historia calamitatum, ed. J. Monfrin, París, J. Vrin, 1962, lín. 1223-1225. «...ad gentes transire disponerem, atque ibi quiete sub quacunque tributi pactione inter inimicos Christi christiane vivere».

22 Historia Calamitatum, ed, cit., línas1215-1216

23 Dialogus, ed. cit., lín. 1216.

24 Ibidem, 1245.

25 Historia Calamitatum, ed. cit., lín. 81

26 Ibidem, 169-170. 
los razonamientos, sino de fiarse exclusivamente de la palabra de las autoridades ${ }^{27}$. ¿Qué decir de la postura de San Bernardo...! Todo esto Abelardo lo tenía muy gravado en su interior. Los discípulos de Abelardo, por el contrario, reclamaban razonamientos humanos y filosóficos, demostraciones no de voces y de vanas palabras, y sostenían que la fe exige la comprensión y que resulta ridículo predicar a los demás aquello que no se comprende mejor que los que le escuchan $^{28}$.

Ahora, en el Dialogus, encontramos los ecos de todas aquellas voces. El filósofo ve en la predicación cristiana el peligro de constreñir a la fuerza la adhesión a la fe más que por convicción racional ${ }^{29}$. Si según las palabras de San Gregorio la fe es sin mérito cuando se basa en la razón, la predicación consagraría entonces, a golpe de autoridad, la dimisión de la razón y su impotencia ${ }^{30}$. Desde este momento todo es posible: necedades ${ }^{31}$, sofismas ${ }^{32}$, abuso de credulidad de la gente. $Y$, a pesar de todo, ¿no es el Dios de los cristianos sophía, logos, verbum? ${ }^{33}$. La fe consistiría en poner las palabras una junto a otra más que en comprender el sentido. ¿Será necesario llegar hasta gloriarse de creer cosas tales que la boca no pueda proferirlas ni concebirlas el espíritu ${ }^{34}$. El filósofo reclama una religión de corazón y no de boca ${ }^{35}$, y en este sentido responde a las palabras de San Gregorio con las de San Antonio: «Puesto que el discernimiento de la razón es la fuente de los escritos, el que posea este discernimiento, no tiene necesidad de escritos» ${ }^{36}$. La razón no tiene necesidad de escritos, tanto más que la Sagrada Escritura, para Abelardo concede al discurso retórico las funciones que la Escritura posee ${ }^{37}$.

La debilidad de la predicación cristiana, como la de la retórica, consiste en apoyarse en argumentos de autoridad: luego, continúa el filósofo, estos argumentos sirven más al orador que al filósofo: «... eos orator magis quam philosophus confugere cogitur» ${ }^{38}$. Boecio, Cicerón y Temistio son citados en este lugar para recordar al cristiano que semejantes argumentos son exteriores, sin valor, sin fuerza, sin ingeniosidad personal ni esfuerzo intelectual y que desembocan más en opiniones que en verdades ${ }^{39}$. Pueden, incluso, encerrar una cierta forma de alienación ${ }^{40}$. Y puesto que son extrínsecos, es decir contingentes y no necesarios, estos argumentos no se deducen de ninguna manera de la unión íntima que existe entre el predicado y el sujeto $^{41}$. Esta crítica de la predicación cristiana, claramente identificada con la retórica, se hace por y a favor de la dialéctica de la que el filósofo canta sus maravillas sirviéndose de diferentes pasajes de obras de San Agustín y así la llama del «arte de disputar» y sirviéndose del $D e$ Ordine «...Disciplina disciplinarum... Hec docet docere, hec docet discere..». ${ }^{42}$. Si concede algún valor a la predicación cristiana es porque la predicación ha podido convertir a la fe a hombres armados de argumentaciones lógicas e instruidos en las artes liberales: «La mejor recomendación en favor de vuestra predicación cristiana es que haya podido convertir a la fe hombres que eran capaces de argumentar de muchas maneras, instruidos en todas las artes li- 
berales y armados de buenas razones» ${ }^{43}$. Esta concesión arrastra al cristiano a la vía del compromiso hasta el punto que poco a poco aceptará conceder lugar destacado a la razón en sus intervenciones. En la medida en que el cristiano acepta colocarse en el mismo terreno que el filósofo, en esa misma medida y en ese momento, el diálogo se convierte en menos polémico y más amistoso. Se produce como una ruptura en el diálogo, hay un corte brusco. El acuerdo es casi completo entre las dos partes. El cristiano ha desertado del campo de la retórica y se ha pasado al de la dialéctica.

A partir de aquí, el cristiano no tiene escrúpulos en citar las Categorias de Aristóteles ${ }^{44}$, los Tópicos de Cicerón ${ }^{45}$; tampoco le importa recurrir a Plotino ${ }^{46}$, a Sócrates ${ }^{47}$ o al Timeo de Platón ${ }^{48}$. Deja entender que está preocupado por el descubrimiento de lo verdadero más que por declaraciones intempestivas y pueriles ${ }^{49}$. Se somete a las leyes de la definición, articula su pensamiento en torno a los conceptos de uno-múltiple, accidente-sustancia ${ }^{50}$, unicidad-eternidad-omnipotencia divina, la iluminación ${ }^{51}$. Arrastrado de modo imperceptible por la problemática del filósofo, el cristiano resbala en los análisis lógico-gramaticales, tales como los enunciados de proposición, la aceptación de las palabras, la semántica de los términos equívocos, las relaciones lenguaje-cosa... ${ }^{52}$. ¿Es una victoria para el filósofo! Puede felicitarse de haber abierto el diálogo y el entendimiento con el cristiano en las mejores condiciones posibles concediéndole, muy hábilmente y con la ayuda de la Retórica de Cicerón, que la Nueva Alianza es superior a la Antigua y que las nuevas leyes son mejores que las antiguas; que el nuevo legislador es superior a los antiguos y que el Hijo está por encima de los profetas ${ }^{53}$.

\section{EL JUDÍO}

La relación del judío con la gramática es menos evidente y las pruebas son menos apremiantes que en los dos casos anteriores. Sin embargo, es necesario plantear la cuestión del modo siguiente: ¿En qué sentido el judío da pie para poder decir que piensa como gramático? ¿Cuáles son los indicios que podrían sugerimos que Abelardo tenía in mente la gramática cuando hace discutir a su filósofo con el judío?

Comencemos primero por ver ¿qué concepción tiene del judío? Es un niño...unius homunculi... ${ }^{54}$ que, incluso adulto, ha guardado una fe infantil, próxima a la fe de los paganos ${ }^{55}$. Es un hombre que coloca las palabras una junto a la otra sin comprenderlas ${ }^{56}$. En esta afirmación debemos ver una alusión a la función esencial del gramático que es precisamente la de asegurar la construcción perfecta de la frase; mientras que la comprensión del sentido, es decir, la ligazón atributiva de la frase, es propio de la dialéctica. Este hombre necesita ser instruido por leyes escritas ${ }^{57}$, reclama signos exteriores y superfluos más que sólidos argumen-

Ibidem, 1326-1330.

lbidem, 1609-1617.

Ibidem, 87-88, 244, 1442.

Ibidem, 1882.

Ibidem, 2062-2063.

Ibidem, 3306.

Ibidem, 1757-1759.

Ibidem, 2510-1557.

Ibidem, 2627-2656.

Ibidem, 3136-3165, 3169-3189, 3381-3400, 3425.

Ibidem, 1174-1181, 1219-1244.

Ibidem, 157.

Ibidem, 100-117.

Ibidem, 131-132.

Ibidem, 222-223. 
tos $^{58}$; cree todavía en lo maravilloso de los milagros sin descubrir ahí la posible ilusión ${ }^{59}$. El judío es el hombre de temprana edad, como el niño de la clase de gramática y en el que la razón no se ha despertado todavía ni goza del libre albedrío ${ }^{60}$. Llegado ya a la madurez y a la libertad del adulto, es el hombre cuya adhesión a la fe viene del amor que le inspiran los de su raza y su pueblo ${ }^{61}$; es el hombre que piensa las relaciones de su pueblo con Dios en términos de servidor-señor: «Servus sum cuiusdam domini..». ${ }^{62}$, esclavo-príncipe y obsesionado de legislación, de castigo, de obediencia ${ }^{63}$. Es el hombre que adivina la felicidad reservada exclusivamente a su pueblo ${ }^{64}$ bajo la forma de un paraíso demasiado terrestre ${ }^{65}$. No es extraño que a esa edad no se sepa discernir ni argumentar ${ }^{66}$, que sea como el animal, esclavo de los sentido: «Los judíos, en efecto, son como animales y esclavos de los sentidos, no tienen ninguna educación filosófica..». ${ }^{67}$, y que la sola exégesis posible no supere el nivel literal y carnal ${ }^{68}$.

Lo que fundamentalmente falta al judío es una libertad mucho más antigua que la de la ley mosaica, más universal, racional y natural ${ }^{69}$. La religión del judío es una religión de lo propio y de lo singular ${ }^{70}$. Le falta la libertad y la universalidad del dialéctico, del hombre que sabe ligar atributivamente las frases, que ha llegado a la madurez, que da prioridad a la razón, que prefiere lo universal y lo necesario...

El judío está de acuerdo que al llegar la madurez, el creyente debe poder fundamentar su fe en razones ${ }^{71}$. Es necesario reconocer que Abelardo nos presenta al judio en el Dialogus con una cierta capacidad de dialéctica ${ }^{72}$, de acuerdo, por otra parte, con su convicción expresada en la Historia Calamitatum, que siempre, y en todo tiempo, ha habido entre los gentiles, los judíos, los cristianos..., hombres que se elevaron por encima de lo vulgar por la fe y por la severidad de las costumbres ${ }^{73}$. Concesiones a parte, el juicio que sobre el pueblo judío tiene Abelardo en el Dialogus es más bien negativo. Pero, ¿en función y en virtud de qué Abelardo formula este juicio?

Antes de nada tenemos que tener en cuenta dos sorpresas: la primera es que el judío no discute con el cristiano, como a primera vista podría parecer ${ }^{74}$; la segunda, es que la crítica del islamismo está totalmente ausente en el debate que sostienen el judío y el filósofo ${ }^{75}$. Yo quiero ver aquí los indicios que pueden permitirnos pensar que el Dialogus, en su totalidad, no se organiza en torno a un contenido teológico y apologético, sino que todo él gira en función de un cierto método y de un sistema mental con el fin de promocionar la salvación del alma y la investigación de la Verdad.

Ibidem, 87-88. 244, 1442.

Ibidem, 1316-1317.

Ibidem, 1943-1947.

Ibidem, 94-95.

Ibidem, 191-196.

Ibidem, 223-230

Ibidem, 135-138.

lbidem, 417-420, 991-994, 1137-1139.

Ibidem, 1315. Al comienzo del Diálogo el filósofo reprocha tanto al cristiano como al judío no superar el

nivel gramatical de la unión de las palabras sin comprender el sentido.

67 Ibidem, 1314.

68 Ibidem, 2792-2795.

69 Ibidem, 909-912, 332-340, 362-365.

70 Ibidem, 576, 579, 582, 587, 901.

71 Ibidem, 174-180.

72 Cfr. M. de GANDILLAC, srt. cit., pág. 297, nota 16.

73 Historia Calamitatum, ed. cit., líns. 496-500.

74 Curiosamente es el filosofo el que da la réplica cristiana a las cuestiones propuestas por el judío.

75 El filósofo jamás hace referencia a un contenido doctrinal musulmán. No es un ateo, es un cristiano convencido, y si polemiza con el cristiano no es para constatar su fe, sino su método. 
El método salvífico del tratado descansa sobre la práctica de las virtudes y sobre las artes del Trivium, a condición de que estas artes culminen en la dialéctica y en la sabiduría. Hay, efectivamente, un orden de progresión requerido en el aprendizaje de las artes para alcanzar la Sabiduría, que coincide con la evolución del niño hacia la madurez y con la serie de edades y sucesión de los tiempos a lo largo de los cuales la humanidad progresa en la inteligencia del universo creado $^{76}$. Por tanto, el comportamiento del judío resiste a esta sucinta pedagogía de la historia y del progreso y se queda estancado en la primera edad, como el niño que frecuenta la escuela del gramático. Hay tres citas que se encuentran en la primera parte del Dialogus que me parecen muy reveladoras a este respecto aunque, como ya he advertido con anterioridad, se trata de indicios y no de pruebas. La primera y la tercera de las citas son de los poetas Horacio y Ovidio, respectivamente, y la segunda de un filósofo no identificado ${ }^{77}$.

Lo que me parece más significativo de todo esto no es tanto que el filósofo eche mano de citas poéticas, sino que no lo haga más que en la primera parte. Otro indicio: todos sabemos que el estudio de los poetas pertenecía a la gramática no solamente para el bene scribendi y el bene loquendi, sino también de cara a la educación moral ${ }^{78}$. En el siglo XII los textos de Horacio y de Ovidio, incluso los versos citados por Abelardo, son utilizados con mucha frecuencia $^{79}$; el primero de Horacio, Epistola I, 2, 69, servía para exhortar a los niños a una formación precoz; el de Ovidio, Amor, III, 4, 17, por su parte, señalaba la distorsión que existe entre el conocimiento del deber y su ejecución ${ }^{80}$. Cuando Abelardo enfrenta al filósofo con el judío sobre los textos relativos al Antiguo Testamento y a los poetas latinos, ¿querrá quedar claro que el judío, si sólo se mueve en el plano de la fe del Antiguo Testamento, está en el plano escolar a nivel de la gramática? Lo único cierto es que estas aportaciones poéticas proporcionan al filósofo una nueva ocasión para criticar la posición del judío. Si reconoce como ineludible que el niño primero crece antes de comprender ${ }^{81}$ que, como dice Horacio «el vaso impregnado muy pronto de un olor lo conservará largo tiempo» ${ }^{82}$, se escandaliza, sin embargo, de que el adulto siga obstinadamente fiel a los comportamientos epistemológicos de la infancia. Por esta razón objeta citando las palabras del filósofo desconocido al que antes aludí: «Guardaos de tener por sacrosanto todo lo que han podido enseñaros cuando fuisteis niños, porque con frecuencia sucede que al aprender a filosofar, con la edad se rechazan las enseñanzas adaptadas a los oídos tiernos» ${ }^{83}$. ¿No es ésta una invitación a abandonar la filosofía moral de los poetas que, por muy útil que sea para el niño, no conviene a la razón del adulto ni a la fe madura del creyente?

En cuanto a la cita de Ovidio, el filósofo se vuelva contra la ley judía. Si el deseo se manifiesta siempre sobre lo prohibido, ¿por qué sería necesario añadir una ley positiva a la ley natural y multiplicar así los riesgos de transgresión ${ }^{84}$. El filósofo hace una nueva invitación al judío a la madurez, a la libertad interior y racional, en una palabra, al intento de crítica. Estaríamos ante una razón crítica frente a una religiosidad.

Haría falta profundizar estas exigencias, probablemente modificarlas, acaso reconducirlas por completo. Pero si todas estas sugerencias e interpretaciones que hemos hecho del Dialogus de Abelardo tienen un mérito, es precisamente el de confirmar lo que J. Jolivet escribía a

\footnotetext{
77 Ibidem, 113, 114-116, 529. diévale, 25 (1958) 60-61.

79 Cfr. Ibidem, págs. 86, 88, 94, 95.

80 Ibidem, págs. 94-95.

81 Dialogus, ed. cit., líns. 111-112.

82 Ibidem, 113.

83 Ibidem, 114-116.

84 Ibidem, 523-530.
}

76 Dialogus, ed. cit., líns. 1941-1963, 117-120.

78 Cfr. Ph. DELHAYE, «Grammatica et Ethica au XIIe siècle» en Recherches de Théologie Ancienne et Mé- 
modo de conclusión en su Comentario del Dialogus: «El pensamiento de Abelardo se matiza y se desarrolla a lo largo de su carrera, pero siempre existen una línea propia y sus temas esenciales» ${ }^{85}$.

Prof. Mariano Brasa Díez Facultad de Filosofía y Letras Dpto. de Filosofía Universidad Autónoma de Madrid 28049 Madrid 